\title{
Rapidly growing giant pilomatricoma in the right parotid region of a pregnant woman
}

\author{
In Suk Koh', \\ Hwa Jin $\mathrm{Cho}^{2}$, \\ Jin Woo Kim ${ }^{1}$ \\ ${ }^{1}$ Department of Plastic and \\ Reconstructive Surgery, Inje University \\ Busan Paik Hospital, Inje University \\ School of Medicine, Busan; \\ ${ }^{2}$ Department of Pathology, Inje \\ University Busan Paik Hospital, Busan, \\ Korea
}

Pilomatricoma is a benign tumor arising from the primitive basal cells of the epidermis that differentiate into hair matrix cells. Mutations in the CTNNB1 gene, which encodes $\beta$-catenin (a protein involved in hair growth), play an etiological role in the development of pilomatricoma. A 34-yearold woman presenting with a mass in the right parotid region underwent an excisional biopsy. The mass was conclusively diagnosed as pilomatricoma. During pregnancy, the mass grew from 1 $\mathrm{cm}$ to $5 \mathrm{~cm}$ in diameter and was accompanied by pain and tenderness. The growth may have been facilitated by the increased production of estrogen and progesterone, which bind to receptors located in the outer root sheath cells of the hair follicles. No recurrence was observed during 6 months of follow-up.

Keywords: Beta catenin / Estrogen / Pilomatricoma / Pregnancy / Progesterone

\section{INTRODUCTION}

Pilomatricoma is a benign skin tumor that arises from the outer root sheath cells of hair follicles [1]. Although pilomatricoma can occur at any age, it predominantly occurs in infancy, adolescence, and the sixth decade of life and beyond [2-4]. It is more common in women than in men and in Caucasians than in Asians. Pilomatricoma clinically manifests as an indolent, solitary, asymptomatic, firm, skin-colored or faintly blue-colored mass with an average diameter of $1 \mathrm{~cm}$. In rare cases, the size of the lesion exceeds $5 \mathrm{~cm}$; such tumors are classified as giant pilomatricomas [2]. Mutations in the CTNNB1 gene, which encodes $\beta$-catenin (a protein involved in hair growth), play a major role in the etiology of pilomatricoma [1]. Trauma and imbalances of sex hormones have also been reported to affect the growth of this type of tumor [5]. Surgical excision is the

\footnotetext{
Correspondence: Jin Woo Kim

Department of Plastic and Reconstructive Surgery, Inje University Busan Paik Hospital, Inje University School of Medicine, 75 Bokji-ro, Busanjin-gu, Busan 47392, Korea

E-mail: jinooda@hanmail.net

Received October 31, 2019 / Revised March 3, 2020 / Accepted March 20, 2020
}

treatment of choice for pilomatricoma, and the recurrence rate is low.

We report a case of a pilomatricoma in the right parotid area that grew rapidly during pregnancy in a 34-year-old woman.

\section{CASE REPORT}

A 34-year-old woman with a mass in the right parotid area presented to the department of plastic surgery at our institution. The mass was approximately $1 \mathrm{~cm}$ in diameter, and the patient declined surgical excision due to the absence of clinical symptoms. However, during the second and third trimesters of pregnancy, the size of the mass increased to $5 \mathrm{~cm}$ (Fig. 1), and it became painful. The growth of the mass stopped after childbirth. Upon palpation of the mass, the patient reported pain radiating from the parotid region to the posterior auricular area. The lesion was warm to the touch, hard, pale-bluish, and lobulated. The patient agreed to undergo surgical excision of the mass due to the exacerbation of her clinical symptoms.

Ultrasonography was performed to determine whether the mass was a parotid tumor, and revealed a heterogenous mass 


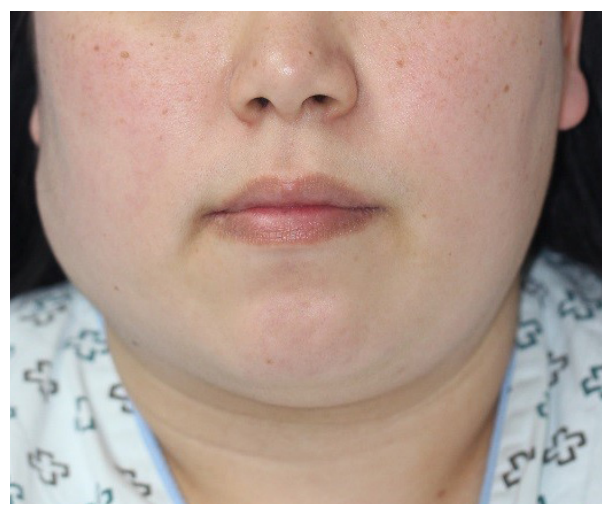

Fig. 1. A 34-year-old woman with a giant pilomatricoma in the right parotid region. The lesion increased to $5 \mathrm{~cm}$ in diameter in the second and third trimesters of pregnancy.

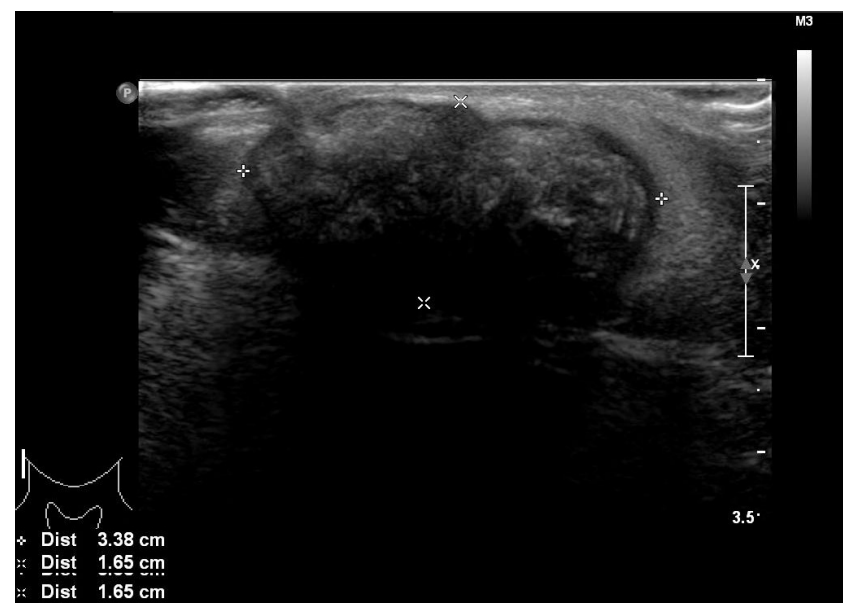

Fig. 2. Ultrasonography showing a heterogeneous lesion separated from the parotid gland.

separated from the parotid gland (Fig. 2). Contrast-enhanced computed tomography of the neck and ultrasound-guided aspiration biopsy were performed. At the right mandibular angle, it appeared as a well-defined, lobulated, and heterogeneously enhanced tumor with a calcified portion in the subcutaneous fat layer and the superficial musculoaponeurotic system (Fig. 3). A punch biopsy revealed features consistent with pilomatricoma, and no tumor cells were found upon ultrasound-guided aspiration biopsy of the cervical lymph nodes.

Under general anesthesia, total excision of the mass was performed through a skin incision (Fig. 4). The mass was located above the superficial musculoaponeurotic system, and it was measured to be $6.0 \times 5.5 \times 1.5 \mathrm{~cm}$. A histopathological examination led to the diagnosis of pilomatricoma on the basis of characteristic findings, including an encapsulated tumor with a central area of abundant eosinophilic anucleated ghost cells and a peripheral area of blue, round basaloid cells. Furthermore, multinucleated giant cells, along with multifocal dystrophic calcifi-
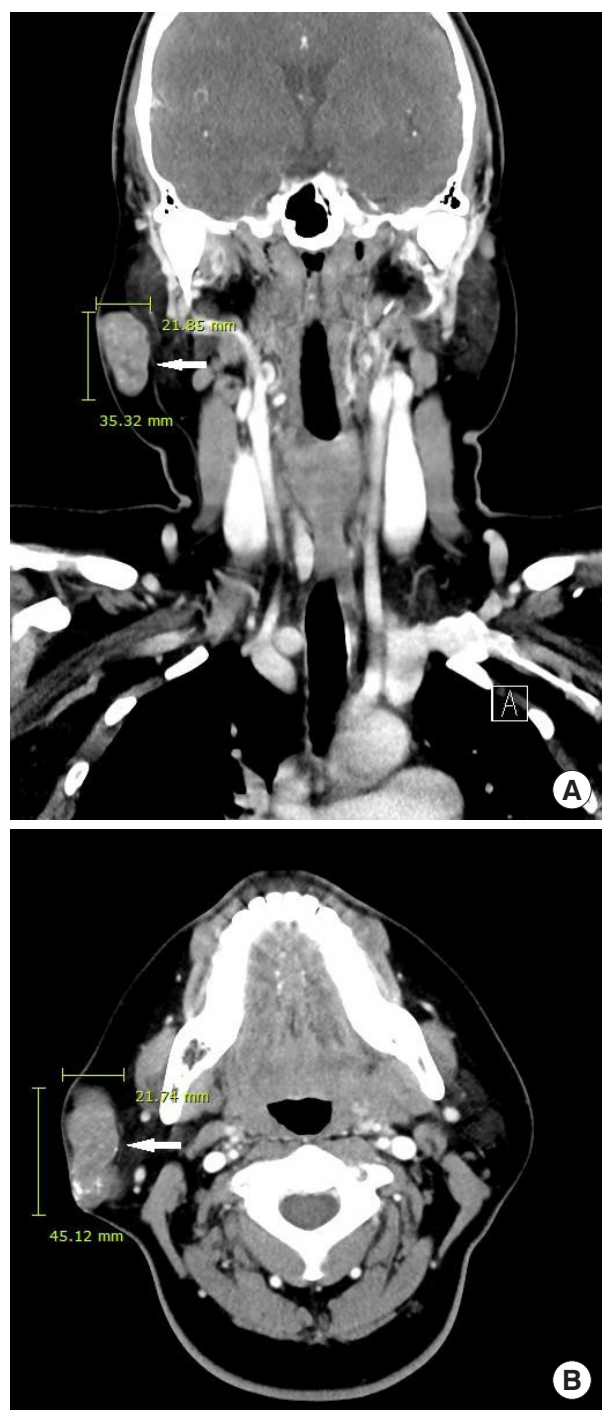

Fig. 3. Coronal (A) and axial (B) views of contrast-enhanced computed tomography of the neck showing a well-defined, lobulated, non-homogeneous lesion in the right parotid area (arrow).

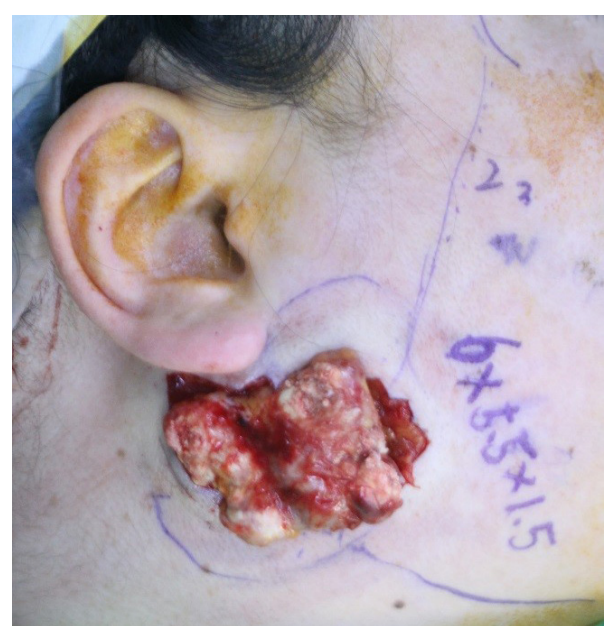

Fig. 4. The mass, which measured $6.0 \times 5.5 \times 1.5 \mathrm{~cm}$, was excised through a skin incision. 

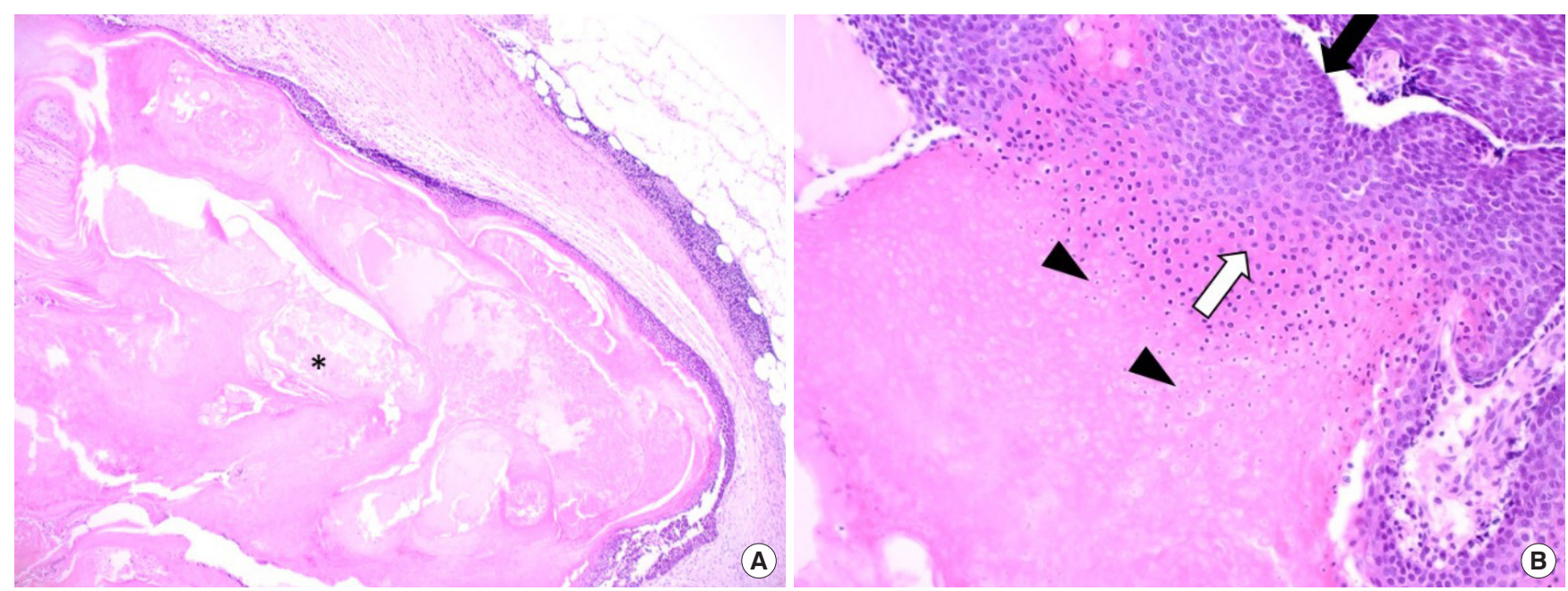

Fig. 5. Microscopic examination revealing typical features of pilomatricoma. (A) A nodular, encapsulated tumor was found in the subcutaneous tissue with central necrosis (asterisk) and peritumoral mild lymphocytic infiltration (H\&E, $\times 40)$. (B) The tumor was composed of outer basaloid and basophilic cells (black arrow) and central eosinophilic cells (white arrow) under the thick fibrous capsule, with anucleated ghost cells (arrowheads) characteristic of pilomatricoma (H\&E, $\times 100)$.

cations and focal foreign body reactions, were observed (Fig. 5). The patient recovered without complications and no recurrence was observed at a 6-month follow-up.

\section{DISCUSSION}

Pilomatricoma is a benign skin tumor originating from the primitive basal cells of the epidermis that differentiate into hair matrix cells. Most pilomatricomas are approximately $1 \mathrm{~cm}$ in diameter, while those measuring $5 \mathrm{~cm}$ or over are classified as giant pilomatricomas [6]. The differential diagnosis for pilomatricoma in the head and neck includes sebaceous cyst, ossifying hematoma, branchial remnant, preauricular sinus, adenopathy, giant cell tumor, chondroma, dermoid cyst, degenerating fibroxanthoma, foreign body reaction, and osteoma cutis [7]. Radiological imaging and a histopathological examination are needed to diagnose pilomatricoma accurately. Its histopathological characteristics include the circular alignment of a cluster of cells (including nucleated basaloid cells) in the periphery and anucleated shadow cells (also known as "ghost cells") in the center [2]. Giant pilomatricomas often occur in association with trauma, and ulceration or focal transepidermal elimination of necrotic tissue material is sometimes observed following a traumatic event.

In this report, we describe the case of a 34-year-old woman with a giant pilomatricoma in the right parotid region. When the mass was first discovered, it was $1 \mathrm{~cm}$ in diameter and asymptomatic. However, during the patient's pregnancy, the mass grew to $5 \mathrm{~cm}$ and became symptomatic. The patient stated that no trauma had occurred in the right parotid area after the mass was initially detected.

Significant sex hormone changes occur during pregnancy. In the first trimester, progesterone, estrogen, and human chorionic gonadotropin (hCG) levels rise. The hCG level declines sharply at 8-11 weeks, whereas the levels of estrogen and progesterone continue to increase in the second trimester. Estrogen and progesterone levels remain elevated in the third trimester, peaking at 23 weeks. In particular, estrogen levels in the third trimester are approximately six times higher than those before pregnancy.

The increase in sex hormone production during pregnancy can promote the growth of pilomatricoma. Estrogen receptors (ER) and progesterone receptors (PR) are expressed in the outer root sheath cells of the hair follicles, from which pilomatricomas originate. Therefore, ER and PR can be expressed in pilomatricomas. Elevated estrogen and progesterone levels translate into higher binding capacity to ER and PR, thereby facilitating the growth of hair follicles [5]. Moreover, pregnancy itself can promote tumor growth. Lymphocytes activated during pregnancy express $\mathrm{PR}$, resulting in the expression of progesterone-induced blocking factor (PIBF), which promotes tumor growth by locally suppressing the antitumor immune response [8].

In this case, a preexisting pilomatricoma grew in the second and third trimesters of pregnancy in a 34-year-old patient. There was no trauma that could have caused tumor growth after the mass had developed. Therefore, the tumor may have grown due to the increased production of estrogen and progesterone during pregnancy. The expression of PIBF during pregnancy may also have promoted tumor growth. Based on our experience with this case, we believe that early excision of pi- 
lomatricoma in pregnant women can prevent tumor growth.

\section{NOTES}

\section{Conflict of interest}

No potential conflict of interest relevant to this article was reported.

\section{Ethical approval}

The study was approved by the Institutional Review Board of Inje University Health Center (IRB No. 19-0174) and performed in accordance with the principles of the Declaration of Helsinki. Written informed consent was obtained.

\section{Patient consent}

The patient provided written informed consent for the publication and the use of her images.

\section{ORCID}

In Suk Koh https://orcid.org/0000-0001-6182-9320

Hwa Jin Cho https://orcid.org/0000-0002-7613-1942 Jin Woo Kim

\section{REFERENCES}

1. Aslan G, Erdogan B, Akoz T, Gorgu M, Seckin S, Terzioglu A. Multiple occurrence of pilomatrixoma. Plast Reconstr Surg 1996;98:510-3.

2. Moehlenbeck FW. Pilomatrixoma (calcifying epithelioma): a statistical study. Arch Dermatol 1973;108:532-4.

3. Lozzi GP, Soyer HP, Fruehauf J, Massone C, Kerl H, Peris K. Giant pilomatricoma. Am J Dermatopathol 2007;29:286-9.

4. Phyu KK, Bradley PJ. Pilomatrixoma in the parotid region. J Laryngol Otol 2001;115:1026-8.

5. Komeda M, Endo Y, Moriwaki S, Kiyokane K, Oba S. A case of giant pilomatricoma appearing during pregnancy. Skin Res 2008;7:322-6.

6. Cozzi DA, d’Ambrosio G, Cirigliano E, Negro V, Iacusso C, Totonelli $\mathrm{G}$, et al. Giant pilomatricoma mimicking a malignant parotid mass. J Pediatr Surg 2011;46:1855-8.

7. Lan MY, Lan MC, Ho CY, Li WY, Lin CZ. Pilomatricoma of the head and neck: a retrospective review of 179 cases. Arch Otolaryngol Head Neck Surg 2003;129:1327-30.

8. Szekeres-Bartho J, Polgar B. PIBF: the double edged sword. Pregnancy and tumor. Am J Reprod Immunol 2010;64:77-86. 